\title{
Transcriptome analysis of epithelioma papulosum cyprini cells after SVCV infection
}

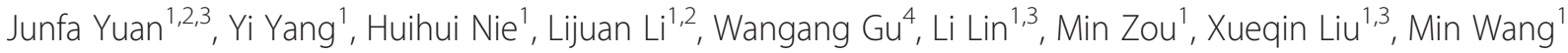 \\ and Zemao $\mathrm{Gu}^{1,2,3^{*}}$
}

\begin{abstract}
Background: Spring viraemia of carp virus (SVCV) has been identified as the causative agent of spring viraemia of carp (SVC) and it has caused significant losses in the cultured common carp (Cyprinus carpio) industry. The molecular mechanisms that underlie the pathogenesis of the disease remain poorly understood. In this study, deep RNA sequencing was used to analyse the transcriptome and gene expression profile of EPC cells at progressive times after SVCV infection. This study addressed the complexity of virus-cell interactions and added knowledge that may help to understand SVCV.
\end{abstract}

Results: A total of 33,849,764 clean data from 36,000,000 sequence reads, with a mean read length $100 \mathrm{bp}$, were obtained. These raw data were assembled into 88,772 contigs. Of these contigs, 19,642 and 25,966 had significant hits to the NR and Uniprot databases where they matched 17,642 and 13,351 unique protein accessions, respectively. At $24 \mathrm{~h}$ post SVCV infection $(1.0 \mathrm{MOI})$, a total of 623 genes were differentially expressed in EPC cells compared to non-infected cells, including 288 up-regulated genes and 335 down-regulated genes. These regulated genes were primarily involved in pathways of apoptosis, oxidative stress and the interferon system, all of which may be involved in viral pathogenesis. In addition, 8 differentially expressed genes (DEGs) were validated by quantitative PCR.

Conclusions: Our findings demonstrate previously unrecognised changes in gene transcription that are associated with SVCV infection in vitro, and many potential cascades identified in the study clearly warrant further experimental investigation. Our data provide new clues to the mechanism of viral susceptibility in EPC cells.

\section{Background}

Spring viraemia of carp virus (SVCV), the causative agent of spring viraemia of carp (SVC), is classified as a member of the family Rhabdoviridae and belongs to the genus Vesiculovirus. SVC is an important disease affecting cyprinids, primarily common carp (Cyprinus carpio). This high-mortality disease is endemic in Europe, North America, and parts of Asia [1]. The major clinical signs for SVCV infection include ascites, and petechiae and ecchymoses in the gills and skin [2].

SVCV exhibits the typical bullet-shaped morphology of a vertebrate rhabdovirus. Its genome is a linear single-stranded, negative-sense RNA that is approximately $11 \mathrm{~kb}$ in length and encodes five structural proteins:

\footnotetext{
* Correspondence: guzemao@mail.hzau.edu.cn

'Department of Aquatic Animal Medicine, College of Fisheries, Huazhong

Agricultural University, Wuhan 430070, People's Republic of China

${ }^{2}$ Freshwater Aquaculture Collaborative Innovation Center of Hubei Province,

Wuhan 430070, People's Republic of China

Full list of author information is available at the end of the article
}

nucleoprotein $(\mathrm{N})$, phosphoprotein $(\mathrm{P})$, matrix protein $(\mathrm{M})$, glycoprotein $(\mathrm{G})$, and RNA-dependent polymerase (L) $[3,4]$.

There have been several studies concerning the pathogenic mechanism (s) involved in SVCV infection have been reported [5-8]. Our previous work demonstrated that the expression of heme oxygenase 1 (HO-1) was down-regulated during SVCV infection in vivo, which suggested that SVCV infection could induce host oxidative stress that might contribute to tissue injury [7]. High-throughput methods, including pathway-targeted microarrays and proteomic analysis, have also been used to scan the host response to viral infection $[9,10]$. These studies suggest that apoptosis, oxidative stress and the interferon (IFN) system may contribute to the mechanisms of the viral pathogenesis. However, a comprehensive identification of the genes involved in viral pathogenesis as well as major signal transduction pathways and intracellular interaction networks remains unavailable. 
Ultrahigh-throughput sequencing technologies permit genome-wide transcriptome analysis at high resolution, and these technologies have been widely used to study pathogenic processes during virus infection, including infections by aquatic viruses $[11,12]$.

New evidence has suggested that the current lineages of the epithelioma papulosum cyprinid (EPC) cell line originated from the fathead minnow (Pimephales promelas) [13]. The temperature growth range, good splitting ratio (1/10) and virus susceptibility make EPC cells highly suitable both for fish pathology and comparative virology studies. The fathead minnow, a species of temperate freshwater fish belonging to the cyprinid family, is widely used as an indicator of environmental water monitoring in ecotoxicological research $[14,15]$. However, only sporadic genetic information about EPC cells or the fathead minnow is available, which might limit further studies with these resources.

In the present study, we present the results from sequencing and assembly of the transcriptome of EPC cells at progressive times after SVCV infection. Genes involved in oxidative stress, apoptosis, and the IFN system as well as nearly all major conserved metazoan signal transduction pathways were largely identified in the EPC transcriptome. It is the first light upon this well known and used fish cell line in fish virology. Additionally, a great number of genes that were differentially expressed upon SVCV infection were obtained and functionally annotated. The gene expression patterns for some of these genes were verified by RT-qPCR. These results offer insight into the complexity of the virus-cell interactions, and add new information that may help to control SVCV infection.

\section{Results}

Transcriptome sequence assembly and analysis

To obtain an overview of the transcriptome of the EPC cells, cDNA samples from normal EPC cells and from EPC cells at different stages during SVCV infection were mixed and sequenced on an Illumina machine. A total of 33,849,764 clean data from 36,000,000 sequence reads, with a mean read length $100 \mathrm{bp}$, was obtained. These raw data were assembled into 88,772 contigs. The mean contig size was $831 \mathrm{bp}$, with lengths ranging from $201 \mathrm{bp}$ to $17,900 \mathrm{bp}$. The contig size distribution is shown in Figure 1.

BLASTX searches for all contigs from EPC cells were performed against several protein databases, including the GenBank non-redundant (NR) and Uniprot databases with an E- value cut-off of $10^{-5}$. Of the 88,772 contigs, 19,642 and 25,966 had significant hits to the NR and Uniprot databases respectively, and they respectively matched 17,642 and 13,351 unique protein accessions.

Further gene ontology (GO) analysis was performed with these contigs. A total of 16,994 unique proteins mapped to 114,154 GO terms: 48,270 unigenes mapped to biological processes, 40,247 unigenes mapped to molecular functions, and 48,151 unigenes mapped to cellular components (Figure 2).

EuKaryotic Orthologous Groups (KOG) classification of the unigenes is important for functional annotation and evolutionary studies. As shown in Figure 3, a total of 12,896 unigenes were finally mapped onto 25 different KOG categories. The largest KOG group was "Signal transduction mechanisms" (2,604 unigenes), followed by "General function prediction only" (1,531 unigenes) and "Posttranslational modification, protein turnover, chaperones" (937 unigenes).

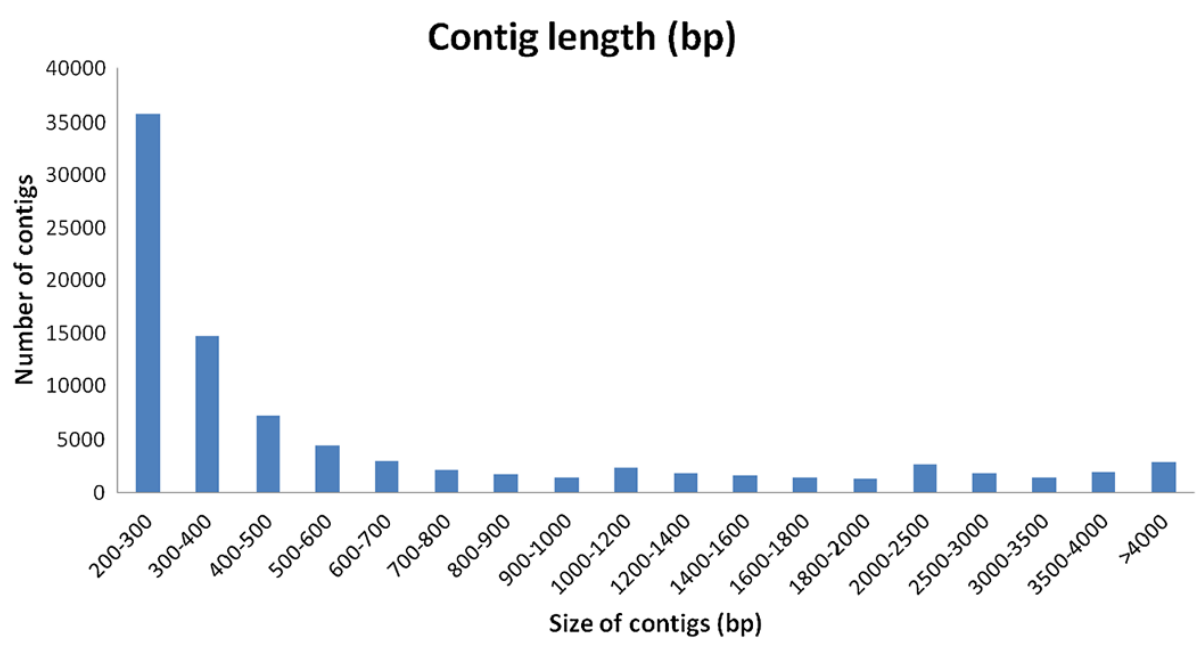

Figure 1 Assembled contig length distribution of the Pimephales promelas transcriptome. The $x$-axis indicates contig size and the $y$-axis indicates the number of contigs of each size. 

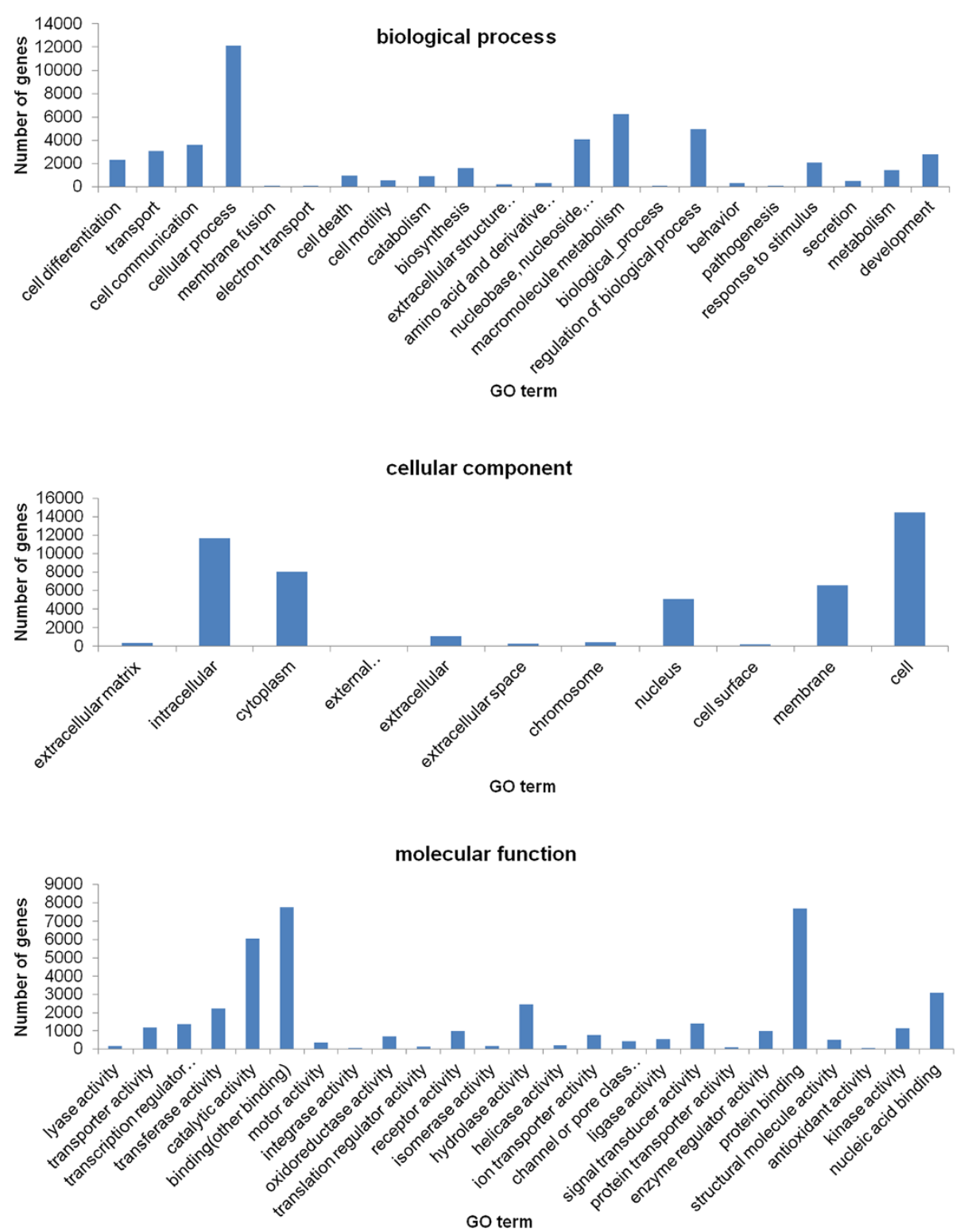

Figure 2 Gene ontology assignments for $P$. promelas. The annotated contigs from $P$. promelas sequencing that matched the three major categories, including biological process, cellular component, and molecular function were shown. The $x$-axis indicates the GO terms and the $y$-axis indicates the number of genes mapped to the indicated GO term.

To obtain more information for predicted functions of the unigenes, the genes from the EPC cells were categorised in the Kyoto Encyclopedia of Genes and Genomes (KEGG) database. A total of 7,349 unigenes was obtained the $\mathrm{KO}$ number (Figure 4).

To assess the evolutionary conservation of the identified unique genes in EPC cells, the number of hits to unique genes in each species of zebrafish, medaka, Tetraodon, Fugu, stickleback, human, mouse, and chicken were compared. A total of 19,018 (70.3\% of total number of unique fathead minnow genes) putative known unique genes was found in all eight species; 20,266 (74.9\%) were found in all five fish species; and 26,986 (99.8\%) were found in at least one of the five fish species (Table 1 and Figure 5), indicating a high level of conservation of gene content among Pimephales promelas and other teleost fish species.

\section{Differentially expressed genes}

To identify differentially expressed genes (DEGs) that potentially are involved in SVCV infection, cDNA libraries were constructed from pooled mRNAs extracted from the SVCV- infected EPC cells $(3 \mathrm{~h}, 6 \mathrm{~h}$ and $24 \mathrm{~h}$ post infection) and non-infected groups. Subsequently, these libraries were sequenced on a Genome Analyzer II. DEGs were 


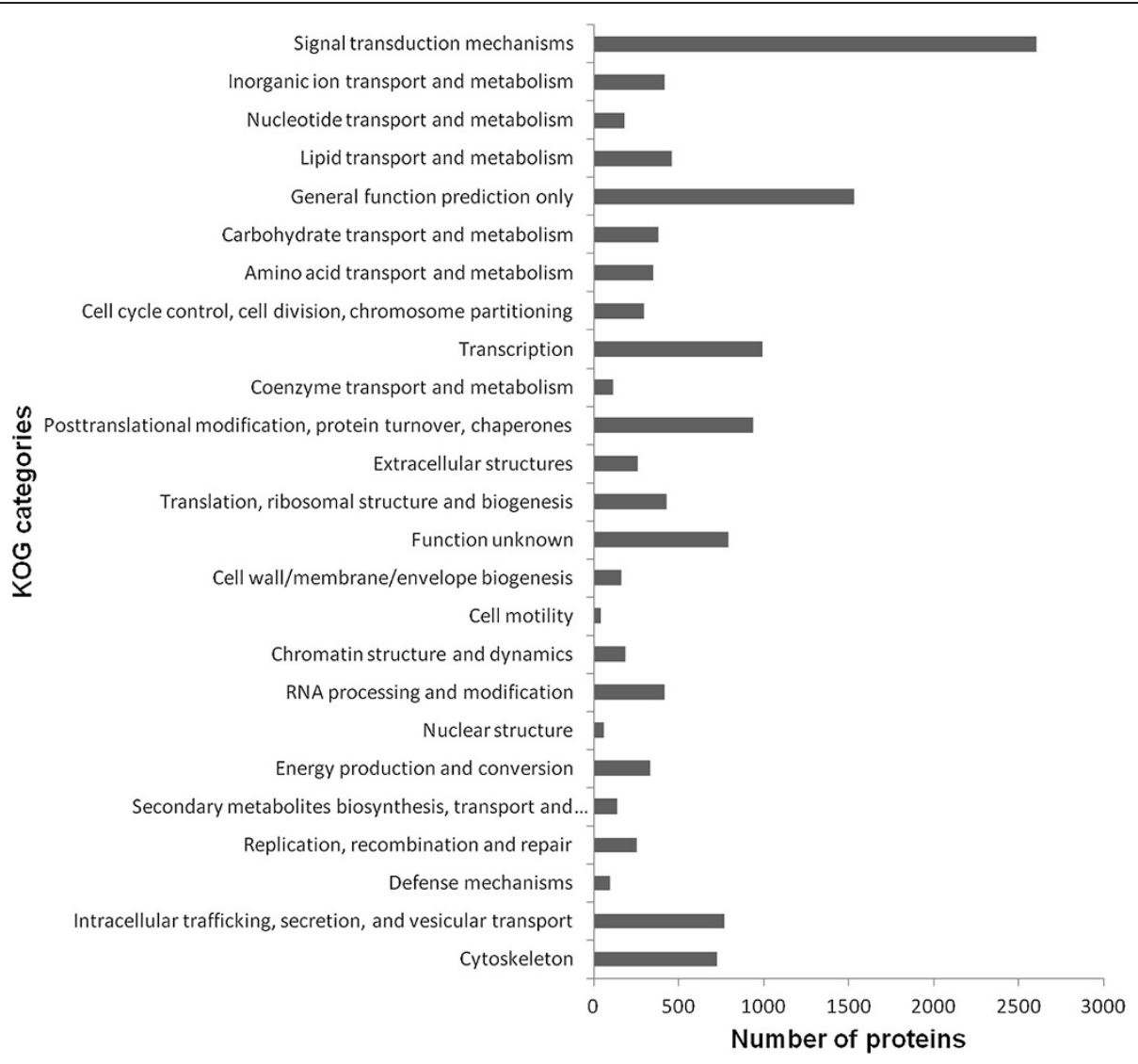

Figure 3 KOG classification of the $P$. promelas transcriptome. A total of 12,896 predicted proteins have a KOG classification among the 25 categories. The $\mathrm{x}$-axis indicates the number of predicted proteins and $\mathrm{y}$-axis indicates the KOG categories.

obtained based on the RPKM of the genes either in SVCV-infection or non-infection group. A gene with an RPKM ratio larger than 2 or smaller than 0.5 was considered to be a DEG $[11,12]$. For the SVCV transcriptome, all five genes encoded by the SVCV genome, including N, P, M, G and L, were transcribed in EPC cells during the entire infection course, though the $\mathrm{M}$ and $\mathrm{L}$ gene were decreased at $6 \mathrm{~h}$ and $24 \mathrm{~h}$ post infection. The statistics of DEGs of host cells between different groups is shown in Table 2. Altogether, 623 genes were differentially expressed in EPC cells at $24 \mathrm{~h}$ post SVCV infection (1.0 MOI) compared to the noninfected cells, including 288 up-regulated genes and 335 down-regulated genes (Additional file 1: Table S2). Among the up-regulated genes, the expression levels of 177 genes were increased more than 4 times, and 58 genes were increased more than 16 times. $C$-fos and kruppel-like factor 2a $(K L F 2 A)$, both associated with stress response, were the genes that showed the highest up-regulation, with an increase of more than 32 times. Among the down-regulated genes, the expression levels of 100 genes were decreased more than 4 times. The most down-regulated gene adrenomedullin 2 ( $A D M 2)$, which associated with oxidative stress, was decreased more than 32 times.

\section{Functional annotation of the DEGs}

To understand the functions of the DEGs and the biological processes involved in SVCV infection, all of the DEGs were mapped to terms in the GO (Figure 6) and KEGG databases (Figure 7). GO analysis showed that a total of 1,748 unigenes had GO annotations. Among the up-regulated genes of host cells at $24 \mathrm{~h}$ post infection, 713 unigenes were mapped to biological processes, 551 unigenes were mapped to cellular components, and 484 unigenes were mapped to molecular functions. Of the biological process related genes, most were involved in cellular processes (141), regulation of biological processes (91), macromolecule metabolism (86), cell communication (58) and responses to stimulus (51). Most of the cellular component related genes were involved in the cell and nucleus. Most of the molecular function related genes were involved in binding (protein or other), transcription regulator and transporter activity. The GO analysis of the down-regulated genes at $24 \mathrm{~h}$ post infection is show in Figure 5B. Among these DEGs at $24 \mathrm{~h}$ post 


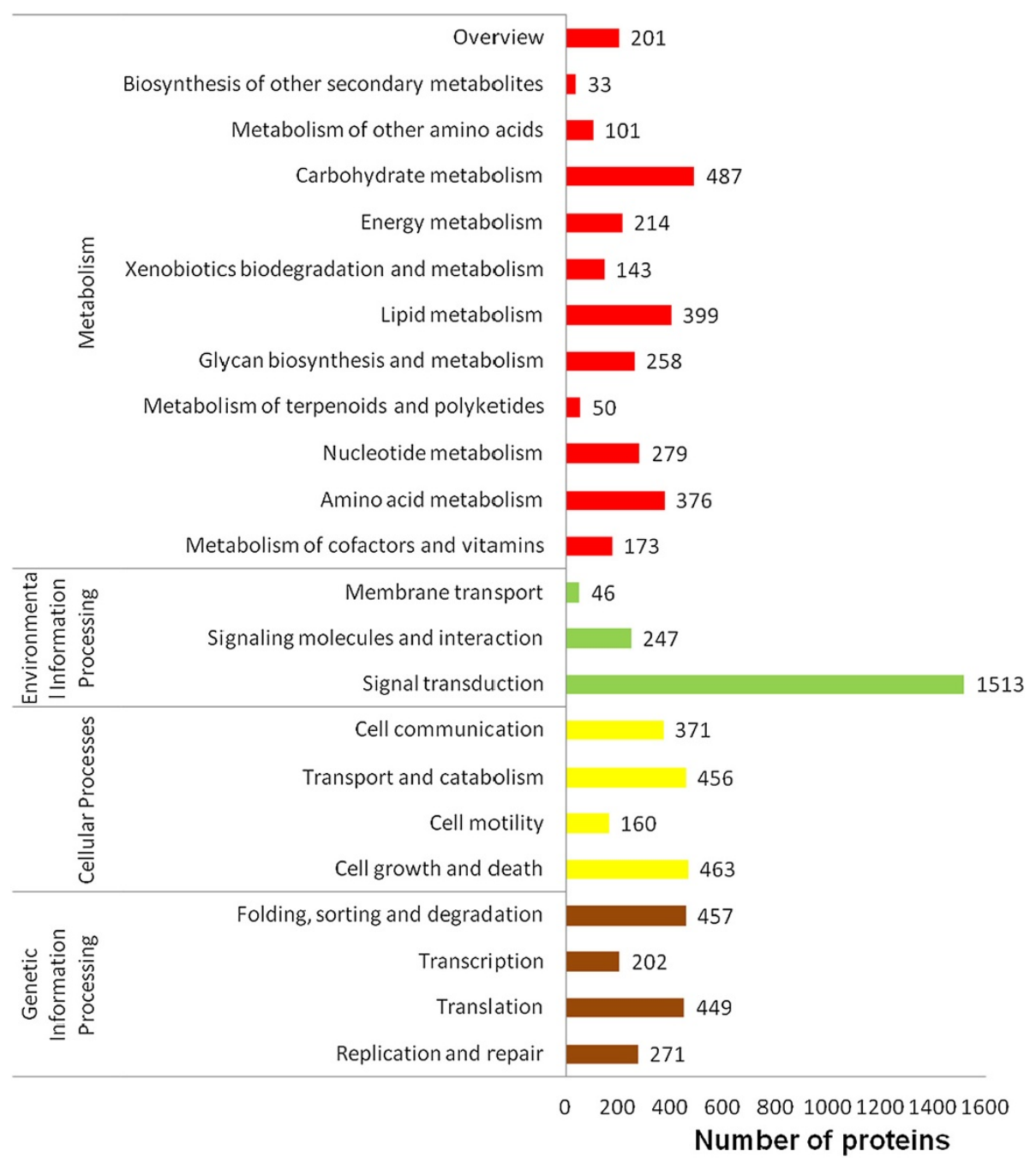

Figure 4 KEGG classification of the $P$. promelas transcriptome. The $x$-axis indicates the number of predicted proteins and the $y$-axis indicates the pathway.

SVCV infection, "nucleus", "intracellular" and "chromosome" in the cellular component ontology, "regulation of biological process", "response to stimulus" and "macromolecule metabolism" in the biological process ontology, and "protein transporter activity" and "structural molecule activity" in the molecular function ontology were enriched by p-value analysis.

KEGG analysis on the DEGs revealed that the upregulated genes at $24 \mathrm{~h}$ post SVCV infection were assigned to 33 KEGG pathways (Figure 6). Nearly $50 \%$ percent of the up-regulated DEGs were assigned to the top 5 pathways as follows: infectious diseases (136), cancer (99), signal transduction (88), immune system(36) and endocrine system (32) ( $Q$ value $<0.05$ ). Additionally, the down-regulated genes were assigned to 37 KEGG pathways, including infectious diseases (50), cancer (35), signal transduction (28), neurodegenerative diseases (27), and endocrine system (26). Altogether, the pathways involved with the DEGs that were enriched for the terms "cell growth and death", "immune disease", "infectious diseases", "endocrine system", "cancer", "neurodegenerative diseases" and "signal transduction" were enriched by p value analysis.

\section{Kinetics of DEGs at different time points post- SVCV infection}

Compared to the non-infected EPC cells, there were 162 up-regulated genes and 27 down-regulated genes at $3 \mathrm{~h}$ post infection (Table 2). When comparing DEGs of host cells between the groups of $6 \mathrm{~h}$ and $3 \mathrm{~h}$ post- infection, the number of up-regulated and down-regulated genes is 11 and 75, respectively. Looking at various genes, many were up-regulated at $3 \mathrm{~h}$ or $6 \mathrm{~h}$, then decreased to the control level. This suggested that SVCV infection stirred up an obvious stress reaction in the early stage of infection. 
Table 1 Summary of the BLASTX (BLSATP) search analysis of $P$. promelas unique sequences

\begin{tabular}{lccl}
\hline Database & Hits* & $\begin{array}{l}\text { Unique } \\
\text { protein }\end{array}$ & $\begin{array}{l}\text { \% of total unique } \\
\text { proteins }\end{array}$ \\
\hline NR $^{1}$ & 25596 & 17642 & \\
$\begin{array}{l}\text { Uniprot } \\
\text { Refseq/Ensembl }\end{array}$ & 19642 & 13351 & \\
$\begin{array}{l}\text { Zebrafish } \\
\text { Medaka }\end{array}$ & 25910 & 15612 & $36.49 \%$ of 42787 \\
Tetraodon & 23006 & 12508 & $50.69 \%$ of 24674 \\
Fugu & 22059 & 12196 & $52.76 \%$ of 23118 \\
Stickleback & 22539 & 14352 & $30.00 \%$ of 47841 \\
Human & 22919 & 12934 & $46.90 \%$ of 27576 \\
Mouse & 21802 & 13534 & $12.97 \%$ of 104310 \\
Chicken & 21782 & 12422 & $24.15 \%$ of 51437 \\
Cumulative unique & 27049 & 17396 & $62.24 \%$ of 16354 \\
\hline
\end{tabular}

The version of indicated species of protein database is the ensemble release-73(ftp://ftp.ensembl.org/pub/release-73/fasta/). *Number of significant alignments using all P. promelas unique sequences as queries to search the listed databases. 'Number of significant alignments using all $P$. promelas unique sequences as queries to search EMBOSS with BLASTp. ${ }^{2}$ Cumulative unique totals were derived from the sum of unique gene/protein identities across all listed species.

For instance, Interleukin-11b, involved in antibacterial and antiviral responses [16], was transiently and sharply up-regulated at $3 \mathrm{~h}$ by SVCV infection, and then decreased to the normal level at $6 \mathrm{~h}$ and $24 \mathrm{~h}$. In contrast to the early stage of SVCV infection, DEGs with modest overlaps were found and resulted in cell damage.

\section{Verification of transcriptome data by RT-qPCR}

To further evaluate our DEG library, 5 up-regulated DEGs and 3 down-regulated DEGs with different fold changes were randomly selected to perform RT-qPCR. Among these selected DEGs, $c$-fos, $c$-Jun, and KLF2A showed the highest up-regulation in mRNA sequencing method. c-Jun in combination with $c$-fos, forms the activator protein 1 (AP-1) early response transcription factor and is associated with stress response. The two other up-regulated genes were caspase 8 (CASP8) and myeloid differentiation primary response 88 (MYD88). These two genes were involved in the regulation of cell death and the innate immune response, respectively. The three selected downregulated DEGs were heat shock protein 47 (HSP47), ubiquinol-cytochrome c reductase, Rieske iron-sulfur polypeptide 1(UQCRFS1) and GSNA. The RT-qPCR results revealed the same expression tendency as the DEG data, despite some quantitative differences in expression level (Figure 8). Among these selected DEGs, the obvious quantitative differences between sequencing and qPCR methods was only observed on the expression of Klf2a. Taken together, qRT-PCR analysis confirmed the tendency detected by the mRNA sequencing analysis.

\section{Discussion}

\section{Global analysis of viral susceptibility genes in EPC transcriptome}

The EPC cell line was established in the 1970s and has become one of the most widely used tools for research on fish virus and the diagnosis of fish diseases. Most of viruses causing systemic infections of fish families and amphibians, as well as Indiana-type vesicular stomatitis virus can propagate in EPC cells [13]. Mining the viral susceptibility genes from the transcriptome data may shed light on the potential mechanism for the broad spectrum sensitivity of this cell line to viruses. Previously, twelve independent studies were summarised to compile a list of human genes important for human immunodeficiency virus (HIV) and other virus infection [17]. A total of 388 human genes that were identified in two or more of these independent studies was suggested to be important for viral infection in mammalian cells. Among these, only 54 homologous genes lacked detectable expression levels in

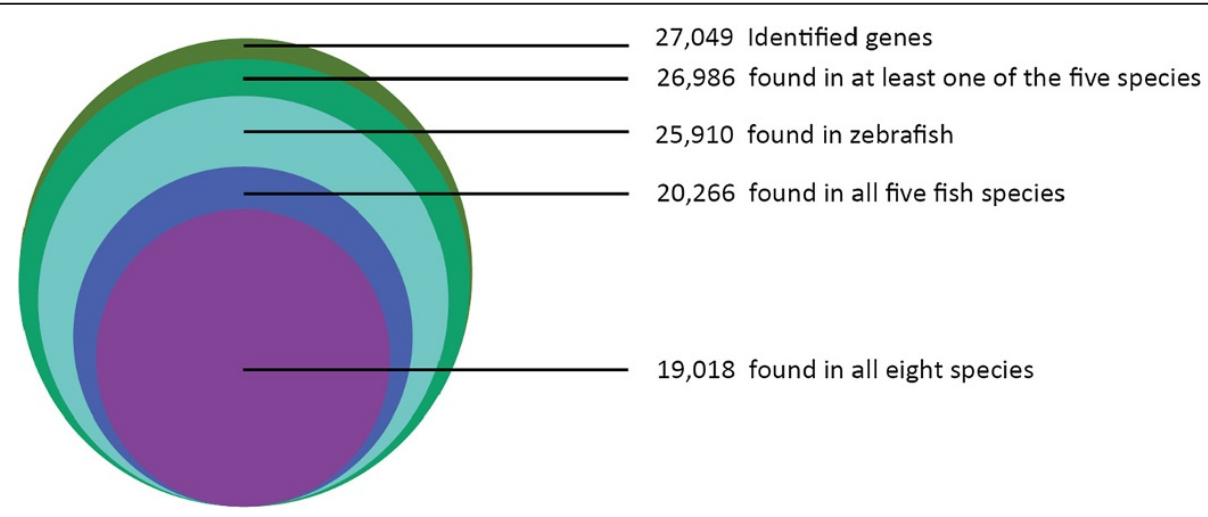

Figure 5 Conservation of $P$. promelas gene identities with other species. Number of $P$. promelas homologous genes identified from other species using BLASTX searches with an E-value cut-off of $10^{-5}$. 
Table 2 Statistics of the differentially expressed genes (DEGs) upon SVCV infection between various time points

\begin{tabular}{lcc}
\hline Sample & Up-regulated & Down-regulated \\
\hline $3 \mathrm{~h}$ Vs Oh & 162 & 27 \\
$6 \mathrm{~h}$ Vs 3h & 11 & 75 \\
$6 \mathrm{~h}$ Vs Oh & 71 & 48 \\
$24 \mathrm{~h}$ Vs 6h & 276 & 360 \\
$24 \mathrm{~h}$ Vs 3h & 240 & 461 \\
$24 \mathrm{~h}$ Vs Oh & 288 & 335 \\
\hline
\end{tabular}

the EPC transcriptome (Additional file 2: Table S3). Of these unexpressed genes, several were specially expressed on mammalian $\mathrm{T}$ cells, natural killer (NK) cells or antigen presenting cells (APC), including CD2, CD4, CD4, CXCR4, CD44, CD86. For instance, CD2 is expressed on the surface of T cells and NK cells, and CD58 is expressed on APC, particularly macrophages. These two adhesion molecules are vitally important for hepatitis B virus (HBV) infection. The gene expression profile of EPC cells suggests that EPC would be one of the best cell models for the study of virus-host interactions. This contrasts with $\mathrm{CHO}-\mathrm{K} 1$, a preferred host cell line for the production of therapeutic proteins, which is naturally resistant to several viral infection; in $\mathrm{CHO}-\mathrm{K} 1$ there were 158 genes lacking detectable expression levels and 4 genes that were not found in its genome [18]. Interestingly, overlaps were found among the non- expressing genes in the EPC and CHO-K1 cell lines. For example, interleukin 1 alpha (IL1 $\alpha)$, responsible for the production of inflammation, as well as the promotion of fever and sepsis, was not expressed in the EPC and CHO-K1 cells.

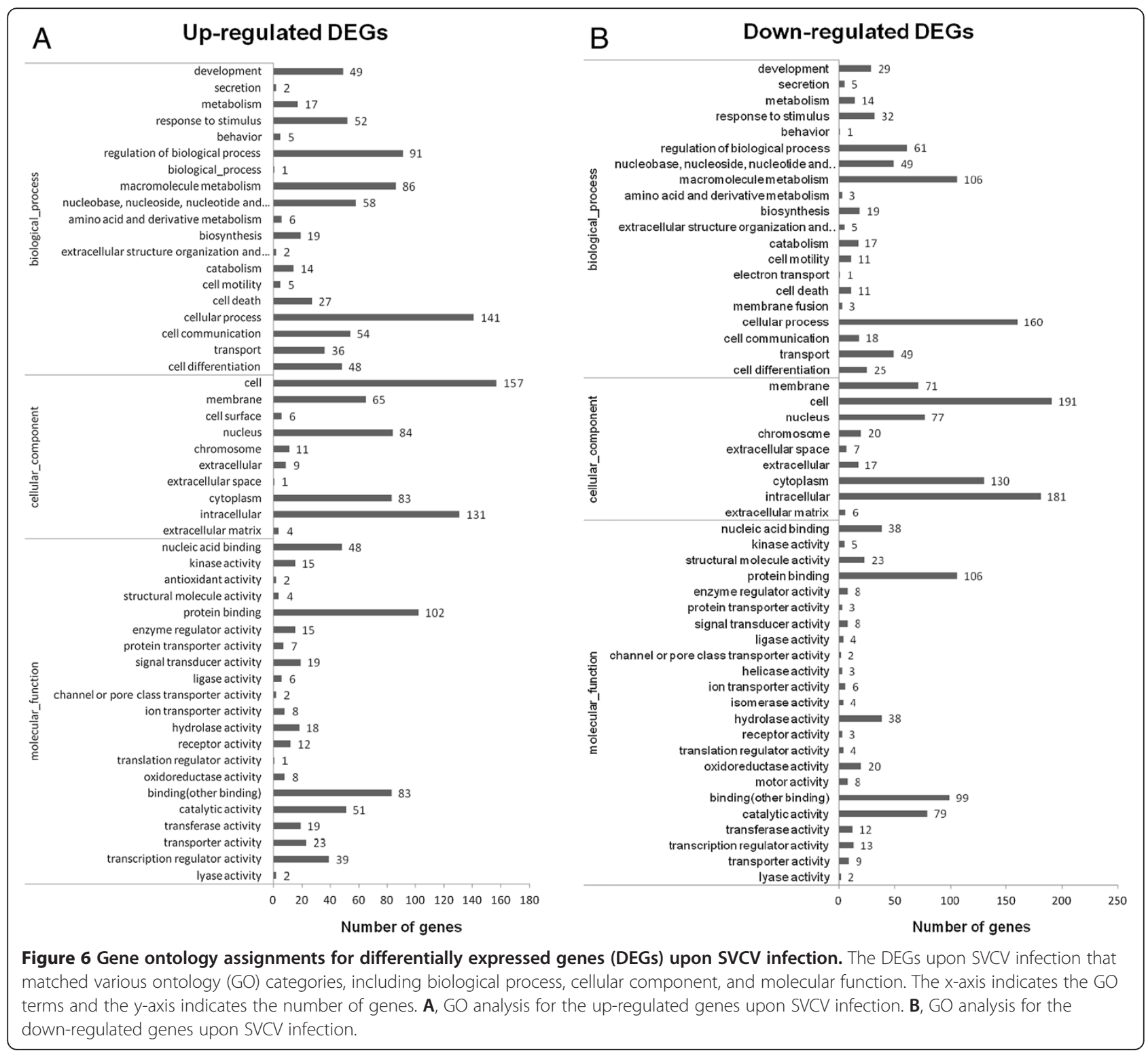



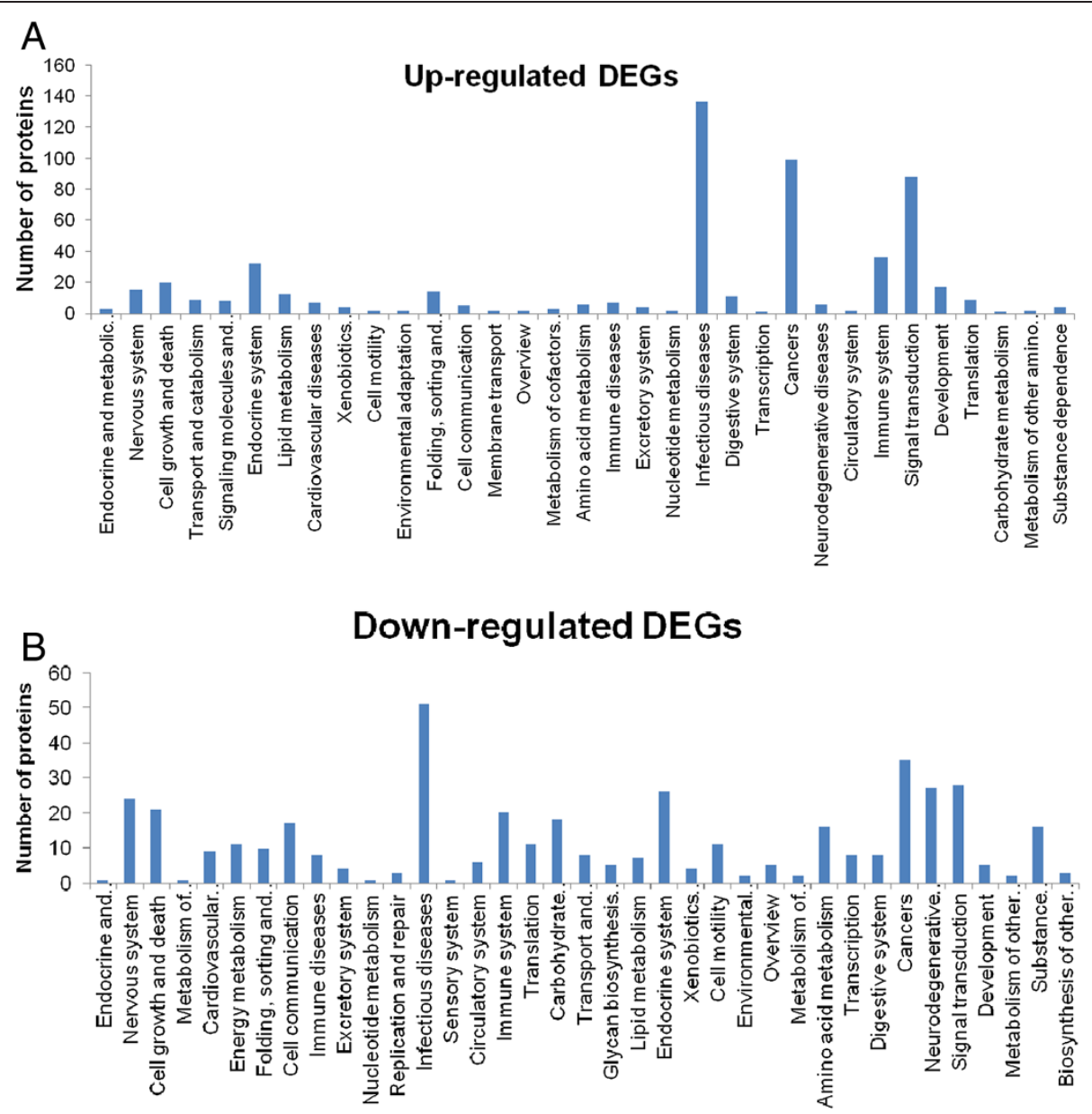

Figure 7 KEGG classification of the differentially expressed genes (DEGs) upon SVCV infection. The KEGG classification of up-regulated genes (A) and down-regulated genes (B) upon SVCV infection is shown. The $x$-axis indicates the pathway and the $y$-axis indicates the number of DEGs.

Another gene of interest that was not expressed in EPC cells. is catalase, a common enzyme found in nearly all living organisms exposed to oxygen. Such information could aid an in-depth analysis of viral susceptibility genes in EPC cells.

\section{Overlaps among different screens for the host responses to SVCV infection}

Until now, two independent studies have investigated the host response to SVCV infection by systematic methods $[9,10]$. Liu et al. revealed 55 dynamically changed proteins in SVCV-infected EPC using 2-DE profile and MS identification [10]. Compared with our results presented here, a total of 10 genes (18\%) overlapped with similar expression profile (Additional file 2: Table S4). Similarly, the overlap between our results and a study which was screened using pathway-target microarrays for zebrafish infected with and survived SVCV was modest [9]. In that study, 16 multipath genes common to more than 6 pathways were identified in 2-day exposed or 30-day survivors of SVCV infection. Among these 16 regulated genes, 7 genes shared a similar expression pattern. However, variation due to 1) experimental noise, 2)timing of sampling, 3) cell type, and 4)different filtering criteria are likely to explain some of the differences among these studies.

\section{Pathophysiology of the EPC response to SVCV infection i. Oxidative stress in SVCV infection}

Oxidative stress has been implicated in the pathogenesis of various neurodegenerative diseases, such as Alzheimer's disease and Parkinson's disease [19]. Oxidative stress occurs in cells when production of reactive oxygen species (ROS) exceeds the cell's endogenous antioxidant defences. Many DNA and RNA viruses can trigger oxidative stress and induce host cell death in infected cells [20-22]. Upon SVCV infection, 19 genes involved in oxidative stress were regulated, including 11 down-regulated genes and 8 up-regulated genes (Table 3). The down-regulated genes 


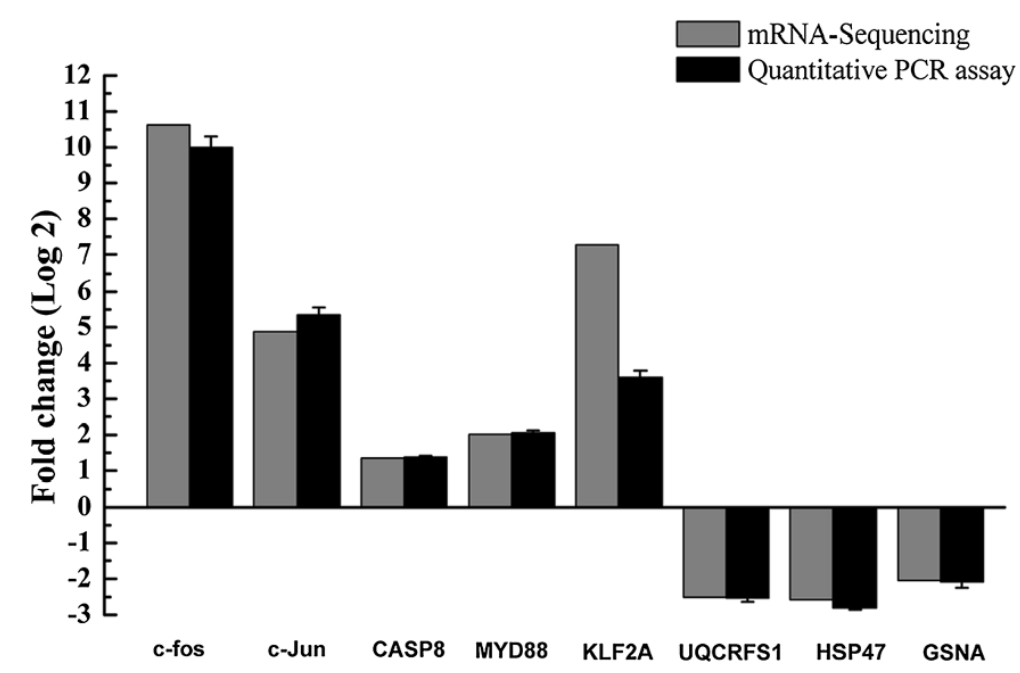

Figure 8 RT-qPCR confirmation of the differentially expressed genes (DEGs) upon SVCV infection. Relative transcript levels (fold changes) of selected DEGs were determined by the real-time PCR, using TATA box binding protein (TBP) as the reference control, and shown by the black bars. Data shown are the mean of triplicates \pm SD. Three parallel experiments were performed and one representative experiment of three is shown. The transcript abundance from DEG data is shown by the grey bars. The minus value means the gene is down-regulated after SVCV infection; while the positive value means the gene is up-regulated in SVCV-infected cells.

included several subunits of the NADH dehydrogenase 1 alpha complex, the first enzyme complex in the electron transport chain located in the inner mitochondrial membrane, i.e. NADH dehydrogenase 1 alpha subcomplex 1 (NDUFA1), NDUFA7, NDUFA11 and NDUFA12, NADH dehydrogenase $\mathrm{Fe}-\mathrm{S}$ protein 5 (NDUFS5), ubiquinolcytochrome c reductase iron-sulphur subunit, and cytochrome b5 type A $(C y b 5 a) . \mathrm{Cu} / \mathrm{Zn}$-superoxide dismutase $(\mathrm{Cu} / \mathrm{Zn} \mathrm{SOD})$, one of the major defences against ROS, was down-regulated more than 2 times post SVCV infection. The up-regulated genes included sestrin 3 (sesn3), uncoupling protein $2(U C P 2)$ and oxidative stress induced growth inhibitor 1 (OSGIN1). Sesn 3 encodes a member of the sestrin family of stress-induced proteins and could reduces the levels of intracellular reactive oxygen species [23]. Uncoupling protein 2 is a member of the larger family of mitochondrial anion carrier proteins and its main function is to control mitochondria-derived reactive oxygen species. OSGIN1, encoding an oxidative stress response protein, is regulated by p53 and is induced by DNA damage. OSGIN1 also regulates apoptosis by inducing cytochrome $\mathrm{c}$ release from mitochondria. These regulated genes indicated that SVCV infection could induce oxidative stress in EPC cells resulting in a series of physiological changes. Another gene of interest is catalase, a common enzyme found in nearly all living organisms exposed to oxygen that is very important in protecting the cell from oxidative damage by ROS; but there was no detectable expression in EPC cells. Altogether, host and virus factors were both contributed to the induction of oxidative stress and the consequent cell damage.

\section{ii. Apoptosis induced by SVCV infection}

Programmed cell death (apoptosis) is one of the most common forms of cell death in multicellular organisms and it plays a pivotal role during normal development and in the regulation of various physiological processes [24]. Two principle pathways of apoptosis exist in mammalian cells, i.e., the extrinsic or receptor-mediated pathway and the intrinsic pathway, which is mediated via mitochondrial and the endoplasmic reticulum. A previous study indicated that EPC cells infected with SVCV undergo apoptosis [6]. In agreement with those results, we found that 19 pro-apoptosis genes were upregulated and 6 anti-apoptosis genes were down-regulated at $24 \mathrm{~h}$ post infection. Most of the up-regulated genes were involved in the death receptor pathway and the mitochondrial pathway, including CASP8, Bcl-2-binding component 3 (BBC3), tyrosine 3-monooxygenase/tryptophan 5 -monooxygenase activation protein, epsilon polypeptide 2 (YWHAE), programmed cell death protein 6 (PDCD6) and many other genes involved in p53 signal transduction (MDM2, GADD45 and sestrin). CASP8 encodes an initiator caspase that directly cleaves downstream effector caspases such as caspase- 3 or cleavaging Bid, a Bcl-2 family protein with a $\mathrm{BH} 3$ domain to initiate a mitochondrial amplification loop [25]. Upon SVCV infection, CASP8 was up-regulated more than 2 times. $B B C 3$, encoding an essential pro-apoptotic protein, was up-regulated more than 32 times at $24 \mathrm{~h}$ post infection. In the pathway of p53 dependent apoptosis, the up-regulation of $B B C 3$ can induce the expression of apoptosis regulator $B A X$ and $B A K$ to trigger apoptosis through the mitochondrial pathway. 
Table 3 List of the differentially expressed genes (DEGs) involved in the pathophysiology of the EPC response to SVCV infection

\begin{tabular}{|c|c|c|c|c|}
\hline Abbr. & Gene description & $\begin{array}{c}\text { *Fold changes } \\
(3 \mathrm{~h}, \log 2)\end{array}$ & $\begin{array}{c}\text { *Fold changes } \\
(6 \mathrm{~h}, \log 2)\end{array}$ & $\begin{array}{l}{ }^{*} \text { Fold change } \\
(24 \text { h Log2) }\end{array}$ \\
\hline \multicolumn{5}{|c|}{ Oxidative stress in SVCV infection } \\
\hline NDUFA12 & NADH dehydrogenase 1 alpha subcomplex 12 & - & - & -1.36 \\
\hline NDUFA1 & NADH dehydrogenase 1 alpha subcomplex 1 & - & - & -1.76 \\
\hline NDUFA11 & NADH dehydrogenase 1 alpha subcomplex subunit 11 & -0.84 & -1.01 & -1.38 \\
\hline NDUFA7 & NADH dehydrogenase 1 alpha subcomplex 7 & - & - & -1.98 \\
\hline UQCRFS1 & Ubiquinol-cytochrome $\mathrm{c}$ reductase iron-sulfur subunit & - & - & -2.51 \\
\hline ATPeVPL & Vacuolar ATP synthase $16 \mathrm{kDa}$ proteolipid subunit & - & - & -1.22 \\
\hline NDUFS5 & NADH dehydrogenase Fe-S protein 5 & - & - & -1.11 \\
\hline COX7B & cytochrome c oxidase subunit VIIb & - & - & -1.25 \\
\hline SOD1 & Cu/Zn-superoxide dismutase & - & - & -1.15 \\
\hline SESN & Sestrin-3 & -1.61 & -0.72 & 2.76 \\
\hline Cyb5a & Cyb5a protein & - & - & -3.06 \\
\hline ENC1 & $\begin{array}{l}\text { Ectodermal-neural cortex 1, a member of the kelch-related } \\
\text { family of actin-binding proteins }\end{array}$ & 1.30 & - & -1.14 \\
\hline OSGIN1 & Oxidative stress-induced growth inhibitor 1 & - & - & 1.39 \\
\hline UCP2 & $\begin{array}{l}\text { Mitochondrial uncoupling protein } 2 \text {, control of } \\
\text { mitochondria-derived reactive oxygen species }\end{array}$ & - & - & 1.16 \\
\hline HSP90 & Heat shock protein HSP 90-alpha & -1.88 & -1.61 & 1.50 \\
\hline C/EBP beta & CCAAT/enhancer binding protein beta & 0.98 & - & 2.96 \\
\hline GADD45A & Growth arrest and DNA-damage-inducible, alpha, a & -0.98 & - & 3.38 \\
\hline GADD45B & Growth arrest and DNA-damage-inducible, beta b & 1.92 & 1.01 & 4.43 \\
\hline Jun-B & Transcription factor jun-B & 1.73 & 2.14 & 4.43 \\
\hline \multicolumn{5}{|c|}{ Apoptosis induced by SVCV infection } \\
\hline NFKBIA & NF-kappaB inhibitor alpha-like protein A & - & - & 3.41 \\
\hline NFKBIB & NF-kappaB inhibitor alpha-like protein B & - & - & 5.32 \\
\hline CSRNP1 & Cysteine/serine-rich nuclear protein 1-like & 1.17 & 0.69 & 3.99 \\
\hline CASP8 & Caspase 8 & - & - & 1.35 \\
\hline TNFRSF1A & Tumor necrosis factor receptor superfamily member $1 \mathrm{~A}$ precursor & - & - & 1.09 \\
\hline $\mathrm{BIRC2}-3$ & Baculoviral IAP repeat-containing 3 & 0.90 & - & 1.43 \\
\hline MYD88 & Myeloid differentiation primary response protein MyD88 & 1.45 & - & 2.02 \\
\hline GADD45A & Growth arrest and DNA-damage-inducible, alpha, a & -0.98 & - & 3.38 \\
\hline GADD45B & Growth arrest and DNA-damage-inducible, beta b & 1.92 & 1.01 & 4.43 \\
\hline OSGIN1 & Oxidative stress-induced growth inhibitor 1 & - & - & 1.39 \\
\hline YWHAE & $\begin{array}{l}\text { Tyrosine 3-monooxygenase/tryptophan 5-monooxygenase } \\
\text { activation protein, epsilon polypeptide } 2,14-3-3 \text { protein epsilon }\end{array}$ & - & - & -1.02 \\
\hline Gelsolin & Scinderin like $b$ & - & - & -1.34 \\
\hline Mdm2 & E3 ubiquitin-protein ligase & - & - & 2.12 \\
\hline PDCD6 & Programmed cell death protein 6 & 1.50 & 0.93 & 1.79 \\
\hline DDIT3 & DNA damage-inducible transcript 3 protein & - & - & 3.57 \\
\hline IRF7 & IFN-regulatory factory 7 & - & - & 3.59 \\
\hline PIM1 & Proto-oncogene serine/threonine-protein kinase pim-1 & 1.70 & 1.60 & 2.58 \\
\hline $\mathrm{BBC} 3$ & BCL2 binding component 3 & - & - & 5.37 \\
\hline$J U N-D$ & Transcription factor jun-D & - & - & 5.45 \\
\hline
\end{tabular}


Table 3 List of the differentially expressed genes (DEGs) involved in the pathophysiology of the EPC response to SVCV infection (Continued)

\begin{tabular}{|c|c|c|c|c|}
\hline Tax1bp1 & Tax1-binding protein 1 homolog B & - & - & 2.35 \\
\hline PHLDA3 & Pleckstrin homology-like domain family B member 3-like & - & - & 2.58 \\
\hline BIRC5 & Baculoviral IAP repeat-containing protein 5 & - & - & -2.13 \\
\hline PAWR & PRKC apoptosis WT1 regulator protein & - & - & -1.32 \\
\hline Mcl1b & Myeloid cell leukemia sequence 1 & - & - & -1.13 \\
\hline Set & Protein SET & - & - & -1.03 \\
\hline \multicolumn{5}{|c|}{ Regulation of the cytoskeleton by SVCV infection } \\
\hline ACTN1 & Alpha-actinin-1 & 0.82 & 0.71 & -1.43 \\
\hline ACTN4 & Alpha-actinin-4 & - & - & -1.45 \\
\hline ACTB & Beta-actin & - & - & -1.35 \\
\hline ARPC5 & Actin related protein $2 / 3$ complex, subunit $5 \mathrm{~A}$ & - & - & -1.22 \\
\hline TUBA8 & Tubulin, alpha 8 like 2 & - & - & -3.32 \\
\hline TUBB6 & Tubulin, beta 6 class $V$ & - & - & -2.70 \\
\hline TUBA4 & Tubulin alpha-4A chain-like & - & - & -3.08 \\
\hline TUBA1 & Tubulin alpha-1C chain & - & - & -2.66 \\
\hline TUBA2 & Tubulin, alpha 2 & - & - & -2.19 \\
\hline TUBB & Tubulin beta-4 chain-like isoform 1 & - & - & -2.04 \\
\hline TUBA & Tubulin alpha 6 & - & - & -2.00 \\
\hline PFN21 & PFN2I protein & - & - & -1.19 \\
\hline RRAS & Ras-related protein & - & - & -1.23 \\
\hline Gelsolin; & Scinderin like b & - & - & -1.34 \\
\hline RAC1 & Ras-related C3 botulinum toxin substrate 1-like & - & - & -1.37 \\
\hline CFL & Cofilin 2, like & - & - & -1.17 \\
\hline PFN2 & Profilin-2-like isoform 2 & - & - & -1.37 \\
\hline GSN & GSNA & - & -0.78 & -2.05 \\
\hline BRICK1 & Probable protein BRICK1-like & - & - & -2.44 \\
\hline $\mathrm{VCL}$ & Vinculin & - & - & -1.34 \\
\hline FLNA; & Vilamin A & - & - & -1.73 \\
\hline COTL1 & Voactosin-like protein & - & - & -2.21 \\
\hline ITGA11 & Integrin alpha-11 & 0.73 & 1.55 & 2.01 \\
\hline \multicolumn{5}{|c|}{ Inhibition of the interferon system } \\
\hline IFNR1 & IFN-regulatory factor 1 & - & - & 4.77 \\
\hline IRF2 & Interferon regulatory factor 2 & - & - & 2.23 \\
\hline IRFBP2 & Interferon regulatory factor 2-binding protein 2-B & - & 0.66 & 2.59 \\
\hline IRF7 & IFN-regulatory factory 7 & - & - & 3.59 \\
\hline
\end{tabular}

"Fold changes refers to the changes of gene expression in response to SVCV infection at the indicated time points, and the minus value means the gene is down-regulated after SVCV infection; while the positive value means the gene is up-regulated in SVCV-infected cells. The dashes (-) indicated that the expression level of certain gene is not changed at the indicated time point post SVCV infection when compared with $0 \mathrm{~h}$ post SVCV infection.

$M D M 2$, an important negative regulator of the p53 tumour suppressor, was up-regulated more than 4 times upon SVCV infection. Meanwhile, several tumor necrosis factor (TNF) signal-related genes were up-regulated including tumour necrosis factor, tumour necrosis factor receptor superfamily member $1 \mathrm{~A} / 11 \mathrm{~A}$ and $11 \mathrm{~B}$, and tumour necrosis factor alpha-induced protein 3/6. This indicated that the TNF signal was activated upon SVCV infection. Several genes involved in the p53 signal pathway were also regulated post SVCV infection. Taken together, SVCV infection could induce apoptosis through the TNF mediated extrinsic pathway and the mitochondrial pathway. Further studies are needed to reveal the detailed mechanism. 


\section{iii. Regulation of the cytoskeleton by SVCV infection}

Viruses use different elements of the cytoskeleton for entry, replication, intracellular transport and budding [26]. Many studies have implicated microfilament, intermediate filaments, and microtubules, as well as proteins that regulate cytoskeleton functions, in the infectious cycles of viruses $[27,28]$. Previous proteomic data revealed that SVCV infection could regulate the cytoskeleton of EPC cells. In our results, approximately 24 cytoskeleton- associated genes were down-regulated, including five microfilament-associated gene (ACTA1, ACTA4, ACTB, FLNA, and $A R P C 5)$ and several microtubule-associated genes (TUBA2, TUBA4, TUBA8, TUB4, and TUB6). These microtubule-associated genes were down-regulated more than 4 times. These genes are also associated with the functional category of cell communication. Among all the regulated genes, only one cytoskeleton-related gene (integrin, alpha 11, ITGA11) was up-regulated at $24 \mathrm{~h}$ post-viral infection. In agreement with the gene expression profile, EPC cells changed to a round sharp and lost the capacity to adhere at $24 \mathrm{~h}$ post-infection. Previous studies have shown that influenza A virus may interact with tubulin and induce disruption of the microtubule network and apoptosis in A549 cells [29]. We speculated that SVCV can also induce cytoskeletal disruption, which may be related to the release of SVCV particles, as well as induce apoptosis of infected cell, but this requires further study.

\section{iv. Inhibition of the interferon system}

The interferon (IFN) response is one of the most fundamental defence mechanisms against viral infection [30]. Viruses, which require cellular machinery for their replication, have evolved different strategies to counteract the action of IFN, particularly by the alteration of IFNsignaling and IFN-induced mediators that are required for virulence [31]. Here, four IFN-signaling genes were up-regulated and no IFN-stimulated genes (ISGs) were regulated untill 24

$\mathrm{h}$ post infection with SVCV. However, we could find many ISGs from the transcriptome of EPC cells, including $\mathrm{MX}$ dynamin-like GTPase 1 (MX1). These upregulated genes include interferon regulatory factor 1 (IRF1), interferon regulatory factor 2 (IRF2), interferon regulatory factor 7 (IRF7), and IFR2 binding protein 2-B $(I B P 2 B)$. The products of IRF1 and IRF2, interferon regulatory factor 1 (IRF-1) and interferon regulatory factor 2 (IRF-2) are structurally similar but functionally distinct transcription factors that bind to the positive regulatory domains I and III (PRDI/III) within the human IFN-beta promoter [32]. IRF-1 serves as an activator of interferon alpha and beta transcription, while IRF-2 competitively inhibits the IRF-1-mediated transcriptional activation of interferon alpha and beta. Both of IRF1 and IRF2 were also up-regulated more than 4 times. More interestingly, IFR2 binding protein 2-B, which can interact with the C-terminal transcriptional repression domain of IRF-2, was up-regulated more than 4 times. The product of IRF7, interferon regulatory factor 7 (IRF-7), has been shown to play a role in the transcriptional activation of virus-inducible cellular genes, including the type I interferon genes [33]. IRF7 was also up-regulated significantly at $24 \mathrm{~h}$ post SVCV infection. In summary, we speculate that SVCV infection might induce the production of IFN but block the function of IFN by inhibiting the production of ISGs through an unknown mechanism.

\section{Conclusions}

In this study, we present the data from sequencing and assembly of the transcriptome of EPC cells at progressive times after SVCV infection. A great number of genes that were differentially expressed upon SVCV infection were obtained and functionally annotated. Further, the gene expression patterns for some of these genes were verified by RT-qPCR. The data present here demonstrate previously unrecognised changes in gene transcription that are associated with SVCV infection in vitro, and many potential cascades identified in the study clearly warrant further experimental investigation. Our data also provide new clues to the mechanism of viral susceptibility in EPC cells.

\section{Methods}

\section{Cells and virus stock}

The EPC cell line (ATCC: CRL-2872) was maintained in Eagle's minimum essential medium (MEM, Invitrogen, Carlsbad, CA) supplemented with $10 \%$ foetal calf serum at $25^{\circ} \mathrm{C}$. SVCV (ATCC: VR -1390), as originally isolated by Fijan et al. [34], was kindly provided by Professor Yuanan Lu (Department of Public Health Sciences, John A. Burns School of Medicine, University of Hawaii at Manoa). Virus multiplication and titration assays were performed as described previously [6].

\section{SVCV infection and sample collection}

For viral infection assays, the SVCV stock was diluted and then used to infect EPC cells at a multiplicity of infection (MOI) of 1.0. Following $1 \mathrm{~h}$ of viral adsorption at $25^{\circ} \mathrm{C}$, the inoculum was removed, cells were washed twice with PBS (pH7.2), and normal medium (MEM containing $10 \%$ FBS) was added. Cells were cultivated at $25^{\circ} \mathrm{C}$ for the time points $(0 \mathrm{~h}, 3 \mathrm{~h}, 6 \mathrm{~h}$, and $24 \mathrm{~h})$ indicated in the figure legends, and then further processed. At each time point in the viral infection assay, three parallel samples were prepared as biological replicates. 
RNA extraction, mRNA purification, and cDNA synthesis

Total RNA was extracted from EPC cells at 0, 3, 6, and $24 \mathrm{~h}$ postinfection in three independent experiments, using TRIzol reagent (Invitrogen, Carlsbad, CA) according to the manufacturer's protocol. The concentration of total RNA was determined using NanoDrop (Thermo Scientific, Waltham, MA), and the RNA integrity value (RIN) was checked using the RNA 6000 Pico LabChip on an Agilent 2100 Bioanalyzer (Agilent, Santa Clara, CA). For mRNA purification, total RNA was incubated with $10 \mathrm{U}$ DNase I (Ambion, Grand Island, NY) at $37^{\circ} \mathrm{C}$ for $1 \mathrm{~h}$, followed by a purification step using a MicroPoly (A) Purist Kit (Ambion, Grand Island, NY) according to the manufacturer's instructions. Then, the purified mRNA was dissolved in RNA storage solution, and the final concentration was determined using NanoDrop. Doublestranded cDNA was synthesised from mRNA according to Ng's full-length cDNA synthesis protocol with some modifications [35]. A GsuI-oligo dT primer was used for the first-strand cDNA synthesis with $10 \mathrm{mg}$ of mRNA and Superscript II reverse transcriptase (Invitrogen, Carlsbad, CA). After incubation at $42^{\circ} \mathrm{C}$ for $1 \mathrm{~h}$, the $5^{\prime}$ - CAP structure of mRNA was oxidised by NaIO4 (Sigma, St. Louis, $\mathrm{MO})$ and ligated to biotin hydrazide, which was used to select complete mRNA/cDNA heterodimers by binding to Dynal M280 beads (Invitrogen, Carlsbad, CA). After the second strand cDNA synthesis, the polyA and 5'- adaptor were removed by GsuI digestion.

\section{cDNA sequencing}

The cDNA was sonicated to the range of 300-500 bp and purified using Ampure beads (Agencourt, USA). The cDNA libraries were prepared with a TruSeq ${ }^{\mathrm{Tm}}$ DNA sample Prep Kit - Set A and were PCR-amplified (15cycles) using a TruSeq PE Cluster kit (Illumina); there were then sequenced on a Genome Analyzer II (Illumina) according to the manufacturer's instructions.

\section{Sequence assembly and annotation}

Raw reads were first cleaned by removing adaptor sequences and low quality sequences $(Q>20)$, and then assembled into EST clusters (contigs) using Trinity with the default assembly parameters (http://trinityrnaseq. sourceforge.net/). The raw data from the Illumina reads have been deposited into NCBI's Sequence Read Archive (SRA) under the accession numbers of SRX546183, SRX546212, SRX546380, SRX547280, and SRX547883.

All contigs were annotated with GetORF from the EMBOSS package (http://emboss.sourceforge.net/) [36]. The ORF of each predicted protein was used for BLASTp searches, against the Swiss-Prot and the NCBI nr databases, setting the e-value threshold to $10^{-5}$. GO annotations were also derived based on sequence similarity with GoPipe (http://www.geneontology.org/) [37]. The COG and KEGG pathway annotations were performed using Blastall software against the Cluster of Orthologous Groups database and the Kyoto Encyclopaedia of Genes and Genomes database (http://www.genome.jp/kegg/) [38]. In this study, we used the default parameters in each approach and no other custom approach was used.

\section{Analysis of gene expression profiles by digital gene expression tag profiling}

To analyse genes that were differentially expressed at different stages of infection, the number of reads for each of the contigs from the indicated samples was converted to Reads per Kilobase per Million (RPKM) [39]. Then, the MA-plot-based method with Random Sampling (MARS) model in the DEGseq package (http://www.bioconductor. org/packages/release/bioc/html/DEGseq.html) was used to calculate the expression abundance of each contig among the indicated samples [40]. We used an false discovery rate (FDR) to determine the threshold of $\mathrm{p}$ value for this analysis. An FDR of 0.001 was considered to have significant expression abundance. For the identification of the pathways that the differentially expressed genes (DEGs) are predicted to participate in, all DEGs were mapped to terms in the KEGG database and searched for significantly enriched KEGG terms compared to the genomic background.

\section{Analysis of gene expression by real-time PCR}

Eight genes were selected for the confirmation of DEG data by real-time PCR, using the SYBR Premix Ex Taq kit (Takara, Japan) according to the manufacturer's instructions in a StepOne machine (Applied Biosystems, Carlsbad, CA). Quantification was performed using the comparative $C_{T}$ method with separate reaction tubes for chosen DEGs and reference (TATA box binding protein, $T B P)$ RNAs. Primers for qPCR were designed with Primer Express software (version 3.0, ABI) based on the target sequences. The primers used for qPCR of the selected DEGs are listed in Additional file 2: Table S1. All reactions were performed in a $10 \mu \mathrm{l}$ volume $(5 \mu \mathrm{l}, 2 \times$ SuperMix Universal; $200 \mathrm{nM}$ of each forward and reverse primer; and $0.2 \mu \mathrm{l}$ ROX reference Dye). A total of 40 cycles were performed. All samples were analysed in triplicate and the relative gene expression data were expressed as the transcription units relative to those of the TBP gene using the $2^{-\mathrm{CT}}$ method [41]. Three parallel experiments were performed and one representative experiment of three is shown.

\section{Additional files}

Additional file 1: Table S2. List of the differentially expressed genes (DEGs) in EPC cells between SVCV infection at $24 \mathrm{~h}$ and $0 \mathrm{~h}$.

Additional file 2: Table S1. Primers used for RT- $q P C R$ verification of DEG data. Table S3. List of the homologous genes involved in viral susceptibility 
that lacked detectable expression levels in the EPC transcriptome. Table S4. List of the differentially expressed genes in SVCV-infected EPC cells which were both identified by MALDI-TOF/TOF and mRNA-sequencing.

\section{Abbreviations}

SVCV: Spring viraemia of carp virus; SVC: Spring viraemia of carp; EPC: Epithelioma papulosum cyprinid; GO: Gene ontology; KOG: EuKaryotic Orthologous Groups; KEGG: Kyoto Encyclopedia of Genes and Genomes; DEGs: Differentially expressed genes; TBP: TATA box binding protein.

\section{Competing interests}

The authors declare that they have no competing interests.

\section{Authors' contributions}

JY and YY carried out all work in the lab and drafted the manuscript. HN, XL, and MW participated in the cell culture and viral infection. MZ and WG made substantial contributions to bioinformatics and statistical analysis. LL and $\mathrm{LL}$ participated in the experiment design and coordination. JY and ZG conceived the study, and participated in its coordination and helped to draft the manuscript. All authors read and approved the final manuscript.

\section{Acknowledgements}

We acknowledge with gratitude to Dr Ken McColl (Australian Animal Health Laboratory, Geelong, Victoria) for critically reading the manuscript. This work was jointly supported by the National Natural Science Foundation of China (31202031), the Special Fund for Agro-scientific Research in the Public Interest (201203086-14), and the Fundamental Research Funds for the Central Universities (2012PY004, 2013PY023, 2013PY070).

\section{Author details}

'Department of Aquatic Animal Medicine, College of Fisheries, Huazhong Agricultural University, Wuhan 430070, People's Republic of China. ${ }^{2}$ Freshwater Aquaculture Collaborative Innovation Center of Hubei Province, Wuhan 430070, People's Republic of China. ${ }^{3}$ Key Lab of Freshwater Animal Breeding, Ministry of Agriculture, Wuhan 430070, People's Republic of China. ${ }^{4}$ Department of Immunology, Zunyi Medical University, Zunyi 563003, People's Republic of China.

Received: 16 May 2014 Accepted: 15 October 2014

Published: 25 October 2014

\section{References}

1. Zhang NZ, Zhang LF, Jiang YN, Zhang T, Xia C: Molecular analysis of spring viraemia of carp virus in China: a fatal aquatic viral disease that might spread in East Asian. PLoS One 2009, 4(7):e6337.

2. Ahne W, Bjorklund HV, Essbauer S, Fijan N, Kurath G, Winton JR: Spring viremia of carp (SVC). Dis Aquat Organ 2002, 52(3):261-272.

3. Teng Y, Liu H, Lv JQ, Fan WH, Zhang QY, Qin QW: Characterization of complete genome sequence of the spring viremia of carp virus isolated from common carp (Cyprinus carpio) in China. Arch Virol 2007, 152(8):1457-1465.

4. Hoffmann B, Schutze H, Mettenleiter TC: Determination of the complete genomic sequence and analysis of the gene products of the virus of Spring Viremia of Carp, a fish rhabdovirus. Virus Res 2002, 84(1-2):89-100

5. Gotesman M, Soliman H, Besch R, El-Matbouli M: Inhibition of spring viraemia of carp virus replication in an Epithelioma papulosum cyprini cell line by RNAi. J Fish Dis 2014. doi:10.1111/jfd.12227.

6. Bjorklund HV, Johansson TR, Rinne A: Rhabdovirus-induced apoptosis in a fish cell line is inhibited by a human endogenous acid cysteine proteinase inhibitor. J Virol 1997, 71(7):5658-5662.

7. Yuan J, Su N, Wang M, Xie P, Shi Z, Li L: Down-regulation of heme oxygenase-1 by SVCV infection. Fish Shellfish Immunol 2012, 32(2):301-306.

8. Adamek M, Rakus KL, Chyb J, Brogden G, Huebner A, Irnazarow I, Steinhagen D: Interferon type I responses to virus infections in carp cells: In vitro studies on Cyprinid herpesvirus 3 and Rhabdovirus carpio infections. Fish Shellfish Immunol 2012, 33(3):482-493.

9. Encinas P, Garcia-Valtanen P, Chinchilla B, Gomez-Casado E, Estepa A, Coll J: Identification of multipath genes differentially expressed in pathwaytargeted microarrays in zebrafish infected and surviving spring viremia carp virus (SVCV) suggest preventive drug candidates. PLoS One 2013, 8(9):e73553.

10. Liu LY, Li Q, Lin L, Wang M, Lu YN, Wang WM, Yuan JF, Li L, Liu XQ: Proteomic analysis of epithelioma papulosum cyprini cells infected with spring viremia of carp virus. Fish Shellfish Immunol 2013, 35(1):26-35.

11. Li S, Zhang X, Sun Z, Li F, Xiang J: Transcriptome analysis on Chinese shrimp Fenneropenaeus chinensis during WSSV acute infection. PLOS One 2013, 8(3):e58627.

12. Zeng D, Chen $X$, Xie D, Zhao Y, Yang C, Li Y, Ma N, Peng M, Yang Q, Liao Z, Wang $H$, Chen $X$ : Transcriptome analysis of Pacific white shrimp (Litopenaeus vannamei) hepatopancreas in response to Taura syndrome Virus (TSV) experimental infection. PLoS One 2013, 8(2):e57515.

13. Winton J, Batts W, de Kinkelin P, LeBerre M, Bremont M, Fijan N: Current lineages of the epithelioma papulosum cyprini (EPC) cell line are contaminated with fathead minnow, Pimephales promelas, cells. J Fish Dis 2010, 33(8):701-704.

14. Perkins EJ, Ankley GT, Crofton KM, Garcia-Reyero N, LaLone CA, Johnson MS, Tietge JE, Villeneuve DL: Current Perspectives on the Use of Alternative Species in Human Health and Ecological Hazard Assessments. Environ Health Persp 2013, 121(9):1002-1010.

15. Ankley GT, Villeneuve DL: The fathead minnow in aquatic toxicology: past, present and future. Aquat Toxicol 2006, 78(1):91-102.

16. Santos MD, Yasuike M, Kondo H, Hirono I, Aoki T: Teleostean IL11b exhibits complementing function to IL11a and expansive involvement in antibacterial and antiviral responses. Mol Immunol 2008, 45(12):3494-3501.

17. Bushman FD, Malani N, Fernandes J, D'Orso I, Cagney G, Diamond TL, Zhou H, Hazuda DJ, Espeseth AS, Konig R, Bandyopadhyay S, Ideker T, Goff SP, Krogan NJ, Frankel AD, Young JA, Chanda SK: Host cell factors in HIV replication: meta-analysis of genome-wide studies. PLOS Pathog 2009, 5(5):e1000437.

18. Xu X, Nagarajan H, Lewis NE, Pan S, Cai Z, Liu X, Chen W, Xie M, Wang W, Hammond S, Andersen MR, Neff N, Passarelli B, Koh W, Fan HC, Wang J, Gui Y, Lee KH, Betenbaugh MJ, Quake SR, Famili I, Palsson BO: The genomic sequence of the Chinese hamster ovary (CHO)-K1 cell line. Nat Biotechnol 2011, 29(8):735-741.

19. Sultana R, Butterfield DA: Role of oxidative stress in the progression of Alzheimer's disease. J Alzheimers Dis 2010, 19(1):341-353.

20. Jackson AC, Kammouni W, Zherebitskaya E, Fernyhough P: Role of oxidative stress in rabies virus infection of adult mouse dorsal root ganglion neurons. J Virol 2010, 84(9):4697-4705.

21. Koike K, Miyoshi $\mathrm{H}$ : Oxidative stress and hepatitis $\mathrm{C}$ viral infection. Hepatol Res 2006, 34(2):65-73.

22. Stehbens WE: Oxidative stress in viral hepatitis and AIDS. Exp Mol Pathol 2004, 77(2):121-132.

23. Lee JH, Budanov AV, Park EJ, Birse R, Kim TE, Perkins GA, Ocorr K, Ellisman $\mathrm{MH}$, Bodmer R, Bier E, Karin M: Sestrin as a Feedback Inhibitor of TOR That Prevents Age-Related Pathologies. Science 2010, 327(5970):1223-1228.

24. Nikoletopoulou V, Markaki M, Palikaras K, Tavernarakis N: Crosstalk between apoptosis, necrosis and autophagy. Biochim Biophys Acta 2013, 1833(12):3448-3459.

25. Fulda S: Caspase-8 in cancer biology and therapy. Cancer Lett 2009, 281(2):128-133.

26. Lehmann MJ, Sherer NM, Marks CB, Pypaert M, Mothes W: Actin- and myosin-driven movement of viruses along filopodia precedes their entry into cells. J Cell Biol 2005, 170(2):317-325.

27. Lyman MG, Enquist LW: Herpesvirus interactions with the host cytoskeleton. J Virol 2009, 83(5):2058-2066.

28. Hyde JL, Gillespie LK, Mackenzie JM: Mouse norovirus 1 utilizes the cytoskeleton network to establish localization of the replication complex proximal to the microtubule organizing center. J Virol 2012, 86(8):4110-4122

29. Han X, Li Z, Chen H, Wang H, Mei L, Wu S, Zhang T, Liu B, Lin X: Influenza virus $A /$ Beijing/501/2009(H1N1) NS1 interacts with beta-tubulin and induces disruption of the microtubule network and apoptosis on A549 cells. PloS One 2012, 7(11):e48340.

30. Randall RE, Goodbourn S: Interferons and viruses: an interplay between induction, signalling, antiviral responses and virus countermeasures. J Gen Virol 2008, 89:1-47

31. Katze $M G, H e Y$, Gale M Jr: Viruses and interferon: a fight for supremacy. Nat Rev Immunol 2002, 2(9):675-687. 
32. Choo A, Palladinetti P, Passioura T, Shen S, Lock R, Symonds G, Dolnikov A: The role of IRF1 and IRF2 transcription factors in leukaemogenesis. Curr Gene Ther 2006, 6(5):543-550.

33. Romieu-Mourez R, Solis M, Nardin A, Goubau D, Baron-Bodo V, Lin R, Massie $B$, Salcedo M, Hiscott J: Distinct roles for IFN regulatory factor (IRF)-3 and IRF-7 in the activation of antitumor properties of human macrophages. Cancer Res 2006, 66(21):10576-10585.

34. Fijan N, Petrinec Z, Sulimanovic D, Zwillenberg LO: Isolation of the viral causative agent from the acute form of infectious dropsy of carp. Vet Arh 1971, 41(5-6):125-138.

35. Ng P, Wei CL, Sung WK, Chiu KP, Lipovich L, Ang CC, Gupta S, Shahab A, Ridwan A, Wong CH, Liu ET, Ruan Y: Gene identification signature (GIS) analysis for transcriptome characterization and genome annotation. Nat Methods 2005, 2(2):105-111.

36. Rice P, Longden I, Bleasby A: EMBOSS: the European Molecular Biology Open Software Suite. Trends Genet 2000, 16(6):276-277.

37. Chen ZZ, Xue CH, Zhu S, Zhou FF, Ling XFB, Liu GP, Chen LB: GoPipe: Streamlined Gene Ontology annotation for batch anonymous sequences with statistics. Prog Biochem Biophys 2005, 32(2):187-190.

38. Kanehisa M, Goto S, Furumichi M, Tanabe M, Hirakawa M: KEGG for representation and analysis of molecular networks involving diseases and drugs. Nucleic Acids Res 2010, 38(Database issue):D355-D360.

39. Mortazavi A, Williams BA, McCue K, Schaeffer L, Wold B: Mapping and quantifying mammalian transcriptomes by RNA-Seq. Nat Methods 2008, 5(7):621-628.

40. Wang L, Feng Z, Wang X, Zhang X: DEGseq: an R package for identifying differentially expressed genes from RNA-seq data. Bioinformatics 2010, 26(1):136-138.

41. Schmittgen TD, Livak KJ: Analyzing real-time PCR data by the comparative C(T) method. Nat Protoc 2008, 3(6):1101-1108

doi:10.1186/1471-2164-15-935

Cite this article as: Yuan et al:: Transcriptome analysis of epithelioma papulosum cyprini cells after SVCV infection. BMC Genomics 2014 15:935.

\section{Submit your next manuscript to BioMed Central and take full advantage of:}

- Convenient online submission

- Thorough peer review

- No space constraints or color figure charges

- Immediate publication on acceptance

- Inclusion in PubMed, CAS, Scopus and Google Scholar

- Research which is freely available for redistribution 